\title{
LAS MICRO Y PEQUEÑAS EMPRESAS ARTESANALES: LA PROBLEMÁTICA DEL MARCO LEGAL DE EXPORTACIÓN EN EL PERÚ EN LOS AÑOS 2010-2011 \\ (1)
}

Niko Cruz Gonazales*

nikturismo@hotmail.com

\begin{abstract}
RESUMEN
La investigación se titula "Las Micro y Pequeñas Empresas Artesanales: La problemática del Marco Legal de Exportación en el Perú, en los años 2010- 2011”. Su objetivo general es determinar el marco jurídico de las micro y pequeñas empresas artesanales con fines de exportación en nuestro país, analizando la normatividad que regula la estructura y funcionamiento de las Mype artesanales. La hipótesis de la investigación considera que la problemática legal (tres legislaciones en menos de 15 años) es la causa principal de la limitada capacidad de las micro y pequeñas empresas dedicadas a la exportación. La metodología utilizada ha revisado la bibliografía y las estadísticas del caso, y se ha aplicado un cuestionario a 260 microempresarios dedicadas a la compra- venta de artesanías, a nivel nacional y para la exportación. Entre las conclusiones se precisan que el marco regulatorio sobre la estructura y funcionamiento de las micro y pequeñas empresas, en general, ha sido modificado en los últimos 15 años, por tres dispositivos legales: la Ley dictada en el gobierno de Fujimori (1997 que crea PROPYME); la Ley № 28015 (2003) dada en el gobierno de Toledo y la promulgada por García, a través del D.L. 1086 y su reglamentación, a través del D.L. № en el año 2008. La última de estas leyes que está en vigencia, elimina PROPYME y las 22 agencias estatales promocionales sustituye, modifica, amplía y/o elimina derechos, formas empresariales de organización y tributación, así como cambios en el régimen laboral de los trabajadores, y en los consiguientes sistemas de de remuneraciones y beneficios sociales, entre otros, conduciendo a una relativa insuficiencia en el uso y aplicación del carácter promocional, así como en un limitado conocimiento por parte de los microempresarios.
\end{abstract}

Palabras Claves: micro y pequeñas empresas- marco legal- estructura y funcionamiento- artesaníasproducción artesanal- exportación.

\section{ABSTRACT}

The investigation is entitled "Micro and Small Craft: The problem of Legal Framework for Export in Peru, in the years 2010- 2011". Its overall objective is to determine the legal framework of the micro and small craft firms for export purposes in our country, analysing the norms that regulates the structure and functioning of the MSES craft. The assumption of the investigation finds that the legal problems (three laws in less than 15 years) is the main cause of the limited capacity of micro and small enterprises engaged in the export.

\footnotetext{
* Doctor en derecho de la Universidad Nacional Federico Villareal, Magister en Administració - UNiversidad Alas Peruanas, Licenciado en turismo-Universidad Nacional San Antonio Abad del Cuzco, Asesor de Proyectos de Inversión Pública y Privada del sector turismo
} 
The methodology has revised the bibliography and statistics of the case, and has been applied a questionnaire to 260 micro entrepreneurs dedicated to the purchase- sell handicrafts, nationally and for export.

Among the findings stipulated that the regulatory on the structure and functioning of the micro and small enterprises, in general, has been amended in the last 15 years, by three legal devices: the Law enacted in the Fujimori government (1997 that creates PROPYME); Act No. 28015 (2003) given in the Government of Toledo and the promulgated by Garcia, through the D. L. 1086 And its Regulations, through the D. L. NO in the year 2008. Among the findings stipulated that the regulatory on the structure and functioning of the micro and small enterprises, in general, has been amended in the last 15 years, by three legal devices: the Law enacted in the Fujimori government (1997 that creates PROPYME); Act No. 28015 (2003) given in the Government of Toledo and the promulgated by Garcia, through the D. L. 1086 And its Regulations, through the D. L. NO in the year 2008.

Keywords: micro and small enterprises- legal framework- structure and functioning- handicraftshandicraft production-export.

\section{INTRODUCCIÓN}

El crecimiento de las micro y pequeñas empresas a nivel nacional e internacional constituye uno de los signos distintivos de la capacidad emprendedora de quienes acceden a instalar, formalizar y desarrollar sus negocios, incorporando mano de obra, contribuyendo al Producto Bruto Nacional e incorporando condiciones de trabajo, no solo en actividades directamente productivas, sino en servicios vinculados al desarrollo de la actividad turística y al fortalecimiento de nuestra identidad cultural, dado que en la producción de artesanías se expresan cultural y artísticamente muchas de las expresiones populares, dado el carácter multicultural de la sociedad peruana.

Sin embargo, el carácter promocional de la normatividad regulatoria, con ser abundante, es también limitante y confusa en nuestro país, habida cuenta de los cambios y modificaciones introducidas muy rápidamente en la estructura y funcionamiento de la micro y pequeñas empresas, provocando efectos negativos y hasta de desconocimiento de sus ventajas y posibilidades de desarrollo. De otro lado el Estado está dejando de intervenir en las actividades promocionales (difusión, publicidad, asistencia crediticia, apoyo técnico, etc.), por lo que los microempresarios se sienten aislados y sin la institucionalidad necesaria para crecer sostenidamente.

La investigación está dividida en cinco capítulos: En el primero se plantea la determinación del problema de investigación, los objetivos de la misma y las limitaciones encontradas en el desarrollo de esta investigación.
En el segundo capítulo desarrollo el marco teórico, exponiendo los fundamentos jurídicos y alcances de las disposiciones legales que alientan y sustentan la actividad artesanal principalmente de los micro y pequeños empresarios dedicados a la exportación. Igualmente se desarrolla las expresiones culturales y de nuestra identidad nacional a partir de la descripción de las principales actividades artesanales en la costa, sierra y selva de nuestro país, así como la importancia económica de las exportaciones de estos productos.

Espero contribuir, con esta investigación a una mejor comprensión de la problemática jurídica y social de los microempresarios artesanales dedicados a la exportación.

\section{MÉTODOS}

Ante la existencia de dos grandes paradigmas de investigación, como son el cuantitativo y el cualitativo, en la presente investigación asumo que es muy importante la articulación y convergencia de las diversas estrategias de investigación en el análisis de una misma realidad, como plantea el profesor sanmarquino Mejía Navarrete. (Problemas Metodológicos de las Ciencias Sociales en el Perú”. UNMSM. Lima. 2002) ${ }^{1}$ Este autor considera que siendo la metodología "un conjunto de procedimientos lógicos (métodos, técnicas, estrategias e instrumentos) sirve para diseñar, ejecutar y evaluar acciones de conocimiento (descripción, explicación, relación y comparación), de explicación (análisis- síntesis, abstracción- concreción, inducción- deducción, experimentación e intervención) y de predicción (cambio, transformación, tendencias, etc.)".

1 Mejía Navarrete. "Problemas Metodológicos de las Ciencias Sociales en el Perú”. UNMSM. Lima. 2002 
Por consiguiente, el investigador, de acuerdo a la particularidad de su objeto de estudio, construye los procedimientos lógicos que lo ayuden a comprender correctamente la realidad, sean estos de naturaleza cuantitativa o cualitativa. Se comprende entonces que "la metodología no es un fin en sí mismo, sino un conjunto de procedimientos lógicos que en todo momento sirven al investigador para orientar su visión del tipo de investigación a realizar y de la utilidad significativa de sus resultados" (Martínez Miguel. Nuevos Métodos de Investigación sobre el Comportamiento Humano. Editorial Universo. Lima. 1998.)²

En base a estas consideraciones, la elaboración del marco teórico consiste en la revisión bibliográfica, documental y de archivo, existente en la Universidad y en otros fondos bibliográficos, como son las revistas especializadas, periódicos, informes, de la información pertinente, las misma que ha sido registrada en fichas y borradores, para posteriormente exponer las definiciones, enfoques y los argumentos de los diversos autores consultados sobre la materia.

Referente a la recolección de información empírica o trabajo de campo, se procede a la elaboración de los instrumentos de recolección de información y a su aprobación antes de la aplicación, generándose la confiabilidad de la información que posteriormente es procesada, en base a las técnicas estadísticas. De esta manera la combinación de información cualitativa y cuantitativa ofrece procesos de interpretación, de la múltiple y variada información que se consigna, permitiendo obtener resultados que sometidos a un razonamiento crítico proporcionan conclusiones y recomendaciones apropiadas al tema de investigación. Por ello estoy de acuerdo con el manejo de los paradigmas metodológicos bajo el concepto de investigación total. Según Hugo Cerda "la investigación total, más que un conjunto de posibilidades reales y potenciales a nivel epistemológico, filosófico, metodológico y operativo, es un acto liberador que permite al investigador sacudirse de una serie de dogmas, estereotipos y fórmulas rígidas, y los cuales le impiden enfrentarse al estudio de la realidad con una actitud despreocupada, y libre de preconcepciones y modelos inmodificables". (Hugo Cerda. La Investigación Total. La Unidad Metodológica en la Investigación Científica. Cooperativa Editorial Magisterio. Colombia. 1997) ${ }^{3}$.

\subsection{TIPO DE INVESTIGACIÓN}

La investigación es Sustantiva porque trata de responder a los problemas sustantivos, es decir esta investigación esta orientada a descubrir, explicar, predecir o retroceder la realidad, considerándose en el nivel de Explicativa que esta orientada al descubrimiento de los factores causales que han podido incidir o afectar la ocurrencia de un fenómeno. ¿Qué efectos? ¿Qué causas? ¿A qué se deben? ¿Por qué? ¿Qué?

Se desarrolla en la Universidad y constituye un aporte por la revisión bibliográfica y recomendaciones que sugieren utilización práctica de estos conocimientos. Y es también aplicada porque sus resultados pueden constituirse en insumos para el desarrollo de políticas públicas o privadas para promocionar las artesanías con fines de exportación.

\subsection{DISEÑNO}

El diseño de investigación utilizado es de tipo Descriptivo-Comparativo- Jurídico, desde que "establece los diversos aspectos, características, causas, factores, etc. del hecho, la funcionalidad y aplicación de la norma jurídica en la realidad social para las micros y pequeñas empresas artesanales.

\subsection{UNIVERSO Y MUESTRA}

El universo o población es la totalidad de elementos o individuos que tienen ciertas características similares.(Artesanos-Instituciones Publicas-Empresas Privadas). La muestra es la parte del universo o población que se selecciona y de la que se obtiene información para el desarrollo de la investigación y sobre la cual se efectuarán la medición y la observación de las variables objeto de estudio.

Para la selección de la muestra se utiliza el siguiente procedimiento estadístico:

$$
n=\frac{N \pi(1-\pi) Z^{2}}{(N-1) \varepsilon^{2}+\pi(1-\pi) Z^{2}}
$$

Donde:

$\mathrm{n}=$ es el tamaño de la muestra que se busca

2 Martínez Miguel. Nuevos Métodos de Investigación sobre el Comportamiento Humano. Editorial Universo. Lima. 1998.

3 Hugo Cerda. La Investigación Total. La Unidad Metodológica en la Investigación Científica. Cooperativa Editorial Magisterio. Colombia. 1997 
$\mathrm{N}$ es el tamaño de la población (micro y pequeñas empresas)

$\mathrm{p}$ es la probabilidad de éxito (proporción de casos en la población con la característica de interés),

e es el error de estimación máximo permisible (margen de error a tolerar),

$Z$ es el valor de la distribución normal estándar para una probabilidad de (1-a/2), donde a es el nivel de significación y (1-a) es el nivel confianza establecido.

De acuerdo con la información disponible, tenemos:

$\mathrm{N}=800$ micro y pequeñas empresas artesanales registradas en Lima Metropolitana.

$\pi=0,9$

$\alpha=0,05 ; 1-\alpha=0,95 ; Z=1,96$

$\varepsilon=0,03$

Reemplazando los valores en la fórmula resulta que:

$$
n=\frac{800(0,9)(0,1)(1,96)^{2}}{799(0,03)^{2}+(0,9)(0,1)(1,96)^{2}}=260
$$

En consecuencia la muestra de micro y pequeñas empresas llega a 260, la que nos servirá como muestra de análisis.

\subsection{HIPÓTESIS DE INVESTIGACIÓN}

\subsubsection{Hipótesis General}

La principal causa es la falta de capacitación en manera legal de los artesanos de la micro y pequeñas empresas artesanales con fines de exportación en el Perú 2010-2011.

\subsubsection{Hipótesis Específicas}

1) El marco jurídico que regula la estructura y funcionamiento de las micro y pequeñas empresas artesanales es muy genérico y confuso, por la inexistencia de referentes promocionales explícitos para fomentar la exportación.

2) La actual estructura administrativa de las micro y pequeñas empresas artesanales definen sus fortalezas por la generación de empleo, capacidad e innovación tecnológica y por el desarrollo de las expresiones de la cultura popular del Perú.

3) Las entidades públicas que debieran promocionar jurídica y financieramente a las micro y pequeñas empresas dedicadas a la exportación, son el Ministerio de Trabajo y de la producción, así como también los gobiernos regionales y locales, además de las entidades financieras existentes.

3.5. VARIABLES, DIMENSIONES E INDICADORES

\begin{tabular}{|c|c|c|c|}
\hline VARIABLES & DIMENSIONES & INDICADORES & $\begin{array}{l}\text { TÉCNICAS DE RECOLEC- } \\
\text { CIÓN DE INFORMACIÓN }\end{array}$ \\
\hline $\begin{array}{l}\text { V. Indepe nd i e n t e: } \\
\text { (X):Marco Legal }\end{array}$ & $\begin{array}{l}\text { Es toda la normatividad (doctrina, } \\
\text { legislación y jurisprudencia) vigente } \\
\text { sobre las micro y pequeñas empresas } \\
\text { en el Perú. }\end{array}$ & $\begin{array}{l}\text { - Ley Mypes } \\
\text { - Ley de Promoción del Turismo } \\
\text { - Ley de Fomento de las Exportacio- } \\
\text { nes (tradicionales y no Tradicionales) }\end{array}$ & - bibliográfia y documentos \\
\hline $\begin{array}{l}\text { V. Dependiente: }(\mathrm{Y}) \text { : Mypes } \\
\text { artesanales }\end{array}$ & $\begin{array}{l}\text { Son todas las unidades productivas, } \\
\text { formales e informales que se dedican } \\
\text { a la producción, elaboración y distri- } \\
\text { bución de productos elaborados por } \\
\text { los propios productores. }\end{array}$ & $\begin{array}{l}\text { - Análisis FODA } \\
\text {-Informalidad empresarial } \\
\text {-Capacidad Empresarial. } \\
\text {-Estructura Ocupacional. } \\
\text { - Distribución por áreas, rubros y } \\
\text { ubicación geográfica. } \\
\text {-Promoción y desarrollo. }\end{array}$ & - bibliográfia y documentos \\
\hline $\begin{array}{l}\text { V. Interviniente: }(\mathrm{Z}) \text { Expor- } \\
\text { tación Artesanales }\end{array}$ & $\begin{array}{l}\text { Es el proceso de venta en el extranjero, } \\
\text { con incentivos tributarios y mecanis- } \\
\text { mos de publicidad y marketing. }\end{array}$ & $\begin{array}{l}\text { - Distribución geográfica. } \\
\text { - Volumen de exportaciones } \\
\text { - incentivos tributarios. } \\
\text { - Niveles de expresión cultural }\end{array}$ & -bibliográfia y documentos \\
\hline
\end{tabular}




\subsection{TÉCNICAS DE RECOLECCIÓN DE DATOS}

a) La Revisión Bibliográfica y Documental.

Se procederá a seleccionar la información existente en los diversos instrumentos jurídicos existentes en los últimos 15 años, (Leyes. Decretos Legislativos y Reglamentaciones). Igualmente se procederá a revisar textos sobre la doctrina, legislación, derecho comparado y jurisprudencia respecto a las micro y pequeñas empresas artesanales dedicadas a la producción y exportación tradicional. Finalmente, se revisarán trabajos de investigación (Tesis) vinculados al tema, así como revistas y artículos seleccionados pertinentes a la problemática de estudio.

\section{b) La Encuesta.}

Procederemos a elaborar un cuestionario de preguntas, destinadas a captar información relevante sobre la problemática legal de los micro y pequeños empresarios, para identificar sus dificultades y limitaciones que enmarca legalmente la estructura y funcionamiento de sus empresas y de sus actividades de exportación.

\subsection{ANÁLISIS DE DATOS}

El análisis e interpretación de la información a recogerse, se hará mediante la utilización del Programa Estadístico SPSS Versión 15, en español. Este programa facilita la tabulación de la información y su procesamiento y exposición en cuadros, tablas y gráficos y la correspondiente presentación de los resultados. Los datos se analizarán en función de las preguntas, objetivos e hipótesis expuestas.

\subsection{PROCEDIMIENTO DE ANÁLISIS DE DATOS}

Se seguirá el siguiente proceso:

a) Obtención de la información de la muestra objeto de investigación.

b) Definición de las variables o criterios para ordenar los datos obtenidos en el trabajo de campo.

c) Definición de las herramientas estadísticas y el programa de computador que se va a utilizar en el procesamiento de datos.

d) Introducción de los datos al computador y activación del Programa SPSS.15 para que procese la información.

e) Impresión del resultado.

\section{ANÁLISIS Y DISCUSIÓN}

\subsection{ANÁLISIS CRÍTICO DE LOS RESULTADOS Y OTRAS PUBLICACIONES}

Teniendo en cuenta la revisión de la literatura existente sobre el tema y los resultados de la aplicación del cuestionario aplicado a micro y pequeños empresarios artesanales, llegamos a constatar los siguientes aspectos:

10 El crecimiento económico de las MYPE a nivel nacional e internacional en el marco de la globalización.

La importancia económica y social de las MYPE se evidencia en la siguiente información oficial: Las MYPES generan en el Perú más del 45\% del $\mathrm{PBI}$, y representa el $99 \%$ de todas las empresas, da empleo al 75\% de la población económicamente activa y genera, aproximadamente, el $40 \%$ del Producto Bruto Interno. Según Fernando Villarán, estos porcentajes son los más altos en América latina y, posiblemente, en el mundo. ("Pequeña Empresa: retos y posibilidades". Seminario en el Congreso de la República. 1999) 4 .

A nivel internacional, tanto el Banco Mundial (BM) como el Banco Interamericano de Desarrollo (BID), destacan que millones de personas en el mundo y, en particular, en América Latina, viven o trabajan vinculados directa e indirectamente en la micro y pequeñas empresas. En países como en el Japón, existen más de un millón y medio de empresas: el 95\% de las cuales es de pequeña y mediana escala en cuanto al nivel de capitalización, número de empleados y ventas anuales.

Dos tercios de las aproximadamente 750,000 fábricas que funcionan en todo el país no emplean más de 9 personas. (Konosuke Matsushita. Claves de un buen gerente. Citado por Nemesio Espinoza Herrera. Ob. Cit. Pág. 40)..$^{5}$

Gran parte de este crecimiento se explica por el apoyo del Estado a partir del desarrollo de políticas públicas que alientan la creación de empresas, principalmente en el sector servicios y como parte de medidas tributarias que alientan este crecimiento sostenido. Aún cuando predomina el modelo de ajuste estructural con estabilidad macroeconómica (o modelo neoliberal), los gobiernos establecen mecanismos indirectos para promover y, a veces, hasta subsidian, vía las tarifas de los servicios públicos, a los microem-

\footnotetext{
4 Seminario "Pequeña Empresa: retos y posibilidades". Congreso de la República. 1999

5 Matsushita, Konosuke. "Claves de un buen gerente". Lima, edic. Kyodai Trading Corporation S. A. 1996.
} 
presarios para que sigan creciendo y compitan con sus similares.

En otros casos disponen de programas estatales que alientan la creación de estas unidades empresariales en aquellas regiones o localidades donde la inversión privada no llega, estableciendo mecanismos promocionales (créditos, y asistencia técnica) para apoyar el surgimiento y mantenimiento de las microempresas, principalmente rurales.

En nuestro país, la percepción que tienen los gobernantes, se orienta a la publicación de disposiciones legales reglamentaristas, pero de relativa aplicación, desde que no se incorpora recursos profesionales y económicos que sustenten o consoliden estas medidas promocionales.

Las respuestas de los propios microempresarios consultados son concluyente: reciben poco apoyo del Estado (66\% precisó que no recibe ningún tipo de apoyo estatal) y su supervivencia en el mercado interno o para exportar depende de su capacidad, experiencia y ubicación en el intercambio comercial.

\section{2o Surgimiento y Consolidación de las Mype en el mercado globalizado.}

Las Mype en el Perú se han originado en la informalidad, principalmente. En los países desarrollados este surgimiento obedece más a las nuevas estrategias de los conglomerados o trasnacionales por ampliar sus economías de escala. Según Sánchez Barajas, el apoyo estatal y privado a la micro y pequeñas empresas, constituyen alternativas para combatir el desempleo, aprovechar la planta productiva existente y sin uso, y, para incorporarlas a las cadenas productivas, que se encuentran en crisis.

Dado que las empresas requieren de una constate provisión de materias primas y de servicios públicos y no públicos, y dado, además, que para ellos el crédito no es un problema, proceden a estimular, vía el Estado, la creación de microempresas, "para apoyar la producción flexible que favoreció la incorporación de la pequeña industria a las cadenas productivas, comerciales y de servicios de las grandes escalas de producción y de exportación" (Genaro Sánchez Barajas. Las Micro y Pequeñas Empresas Mexicanas ante la
Crisis del Paradigma Económico del 2009. F.C.E. México. D.F. 2009). ${ }^{6}$

El apoyo a las Mype en el Perú, desde el Estado se orientó en el periodo 1997-2008, a través de PROMYPE y sus 22 programas estatales, en la creación de un vice ministerio en el Ministerio de Trabajo y el Empleo, el aumento de capital a Cofide, y la incorporación del financiamiento privado, etc. En la actualidad, se ha dejado todo el apoyo a la iniciativa privada.

Esta situación es percibida por los microempresarios consultados, donde su respuestas son contundentes: El 57\% considera que la nueva ley de las MYPES no facilita la creación y desarrollo de su negocio y un $34 \%$ obvió responder la pregunta por no sentirse involucrado en los supuestos beneficios que la ley otorga.

El $77 \%$ no recibe crédito de entidades financieras y los que solicitaron crédito recurren a la banca privada o a las cajas municipales en $23 \%$.

"El caso de las Pyme en el Perú, demuestra, que siempre han sido consideradas como un asunto de quinta categoría, no solo por el Estado sino por la sociedad misma y, cual paria, las Pyme han venido desarrollándose hasta alcanzar la trascendencia en la vida nacional que hoy tiene gracias a la capacidad y talento de millones de pequeños y microempresarios peruanos anónimos". ("Perú: el sector informal frente al reto de la modernización. Organización Internacional del Trabajo (OIT). Lima. 1998) ${ }^{7}$.

Ante esta dramática situación, es que los microempresarios artesanales dedicadas a la exportación consideran que es muy poco o nulo lo que reciben como apoyo promoción por parte del Estado. Si bien están funcionando por más de 5 años (57\%), empezaron informalmente (63\%, y lo hicieron porque los altos impuestos (34\%), el desconocimiento de la Ley (15\%) y los trámites tediosos, largos y costosos (7\%), limitaron su capacidad personal para iniciarse como cualquier otra empresa legalmente establecida.

La principal desventaja de esta informalidad radicó en la falta de crédito y en el decomiso de su mercadería ( $23 \%$ en ambos casos) así como en la imposibilidad de acceder al crédito (17\%). Una vez conseguida la formalización de su empresa,

\footnotetext{
6 Sánchez Barajas, Genaro.” Las Micro y Pequeñas Empresas Mexicanas ante la Crisis del Paradigma Económico del 2009”. F.C.E. México. D.F. 2009

7 OIT. "Perú: el sector informal frente al reto de la modernización". Organización Internacional del Trabajo Lima. 1998
} 
el 23\% pudo acceder a dicho crédito, pero además de ello, pudo superar los problemas municipales, conseguir otros clientes y poder exportar (14\%).

De hecho la formalización, con todo lo que acarrea consigo, trae muchos beneficios cuando se trata de crecer y consolidarse.

\section{Las MYPE Artesanales de Exportación.}

La producción de artesanías en un país pluricultural y biodiverso como el Perú, y con atractivos turísticos tan diversos en sus contextos locales y regionales y con trascendencia histórico-cultural, ha hecho de esta actividad, un renglón productivo extraordinario, en que se concretizan las diversas expresiones culturales, vinculadas a la cerámica, orfebrería, tejidos, gastronomía, confecciones diversas, adornos, bisutería, joyería, artesanía de madera, pinturas, esculturas, miniaturas, música, danzas, estampas folklóricas, etc.

La producción artesanal está muy vinculada a la actividad turísticas, desde que sus manifestaciones se objetivizan en creaciones artísticas que se llevan los turistas (Souvenirs) o que se convierten en potenciales clientes cuando se hallan en sus respectivos países y desean comprar, coleccionar y regalar estas expresiones de la creatividad e imaginación popular.

Pero, en la condición de exportador, hay que distinguir la que efectúa el productor directo, a través de sus asociaciones (cooperativas de venta y similares) y las que efectúa el empresario, que acopia, compra y vende directamente, beneficiándose con el intercambio. Y sin intervenir en la producción de las mismas. Aquí se pierde el sentido de la identidad cultural, porque este tipo de empresario- exportador, orienta su exportación a los gustos modernos de sus clientes, sin tener en cuenta el mensaje cultural de quienes los producen, convirtiendo su actividad comercial como cualquier otro rubro.

De cualquier forma, se requiere una decisiva política de promoción de este sector, habida cuenta de sus aportes a la balanza de pagos, a la generación de empleo y a la valoración continua de nuestro patrimonio cultural e identidad nacional. Para ello se requiere de, según Villarán "medidas e instrumentos específicos que van desde la dinamización de los mercados de salida de sus productos, hasta la consolidación de los mercados para alcanzar las condiciones de competitividad en los mercados en los que hoy se actúa y así enfrentar los retos de la globalización" (Fernando Villarán. Las Pyme en la estructura empresarial peruana. Servicios para el Desarrollo (SASE). Perú. 2000) ${ }^{8}$.

Los microempresarios exportadores, perciben que se encuentran aislados, por no decir abandonados, de apoyo estatal. Si se tiene en cuenta que básicamente su productos son elaborados en provincias $(63 \%)$, que principalmente sus exportaciones son de tejidos y similares (29\%) de cerámicas (17\%) y de artículos tradicionales como los retablos ayacuchanos, o bordados de Huancayo, etc. (29\%), opinan que la demanda de sus productos en el extranjero no son permanentes, ya que en un $37 \%$ trabajan por pedidos y en un $12 \%$ por campañas, lo que demuestra una relativa inestabilidad de su capacidad exportadora. Otro aspecto a considerar es la relación de los microempresarios dedicados a la exportación respecto a Adex.

Los exportadores peruanos están nucleados en la Asociación de Exportadores (Adex) y sus relaciones con los artesanos que se vinculan con la exportación de sus productos, es a través de programas específicos en los que se apoya, asesora y promociona la mejor venta de sus productos. Pero, si bien existen algunas asociaciones de tiendas comerciales de productos artesanales, no existe a nivel nacional ninguna entidad representativa y aglutinante de los exportadores artesanales que pudieran actuar como una plataforma comercial, para encontrar nuevos clientes, revalorar los productos con mayor valor agregado y, sobretodo, mejorar los ingresos económicos de los artesanos, quienes ven en el mercado nacional e internacional una potencialidad enorme para expandir sus negocios y revalorar sus expresiones artísticas, a través de mejores precios, mejores ingresos y mayor calidad de vida.

\section{4o Apoyo Crediticio y Técnico}

Pasar de una actividad microempresarial orientada al consumo nacional hacia una economía de exportación, es un salto que exige grandes esfuerzos, principalmente institucionales, debido al volumen de la demanda, a la calidad de los productos y al valor agregado en cada uno de ellos. Pero, además, se requiere de estrategias promocionales y de publicidad o marketing para las artesanías en las grandes ferias mundiales. Ello es

8 Villarán Fernando. Las PYME en la estructura empresarial peruana. Servicios para el Desarrollo (SASE). Perú. 2000) 
factible en la medida que exista el financiamiento y apoyo para crecer sostenidamente y solventar con éxito las demandas del mercado mundial y, por supuesto, nacional.

Una Encuesta elaborada por la Sociedad Nacional de Industrias (SIN) en 1999, sobre una muestra de 100 empresas calificadas como PYMES (micro, pequeñas y medianas) señalan que entre los principales problemas enfrentados actualmente por los empresarios de este sector se encuentran: falta de liquidez (29\%), poca demanda de los clientes (18\%), competencia desleal (16\%), inestabilidad en el mercado(7\%), falta de financiamiento (/\%), trabas de los Municipios (5\%), falta de servicios básicos, etc.).

Si tomamos en cuenta estas referencias, podemos señalar que el aspecto de financiamiento es vital para la subsistencia y crecimiento de las Mype. Y la demanda por un mayor apoyo por el Estado, es reclamada por más del $50 \%$ de las empresas consultadas.

En nuestro Cuestionario, encontramos respuestas que señalan en un $77 \%$ que no reciben crédito financiero (Cuadro № 13) y que cuando éste fue solicitado se orientó al $14 \%$ de los que recibieron crédito, determinándose así el poco impacto del crédito en el funcionamiento de estas unidades productivas. En este sentido los exportadores artesanales no recurren a mecanismos financieros porque su producción acumulada no tiene una demanda permanente en el mercado mundial.

En consecuencia, "el problema de la pequeña empresa, no es su tamaño, sino su aislamiento". Esta apreciación indica que teniendo en cuenta un escenario económico dominado por la globalización, hace que las características y condiciones actuales de la economía hacen muy difícil la permanencia de las pequeñas empresas que se mantienen solas, sin contacto con empresas más grandes y sin instituciones de apoyo.

"Para ello se requieren una serie de medidas e instrumentos específicos que van desde la actuación en los mercados de sus productos hasta la consolidación de los mercados de servicios necesarios para alcanzar las condiciones de competitividad en los mercados globalizados donde actúa".

Específicamente en cuanto a las instituciones de apoyo crediticio, se tiene una aglomeración de entidades, donde cada una funciona aisladamente, compitiendo para colocar sus préstamos, pero sin ninguna estrategia institucional de desarrollo para el mediano y el largo plazo.

Así tenemos más de 50 instituciones especializadas, un Banco (MIBANCO), 13 Cajas Municipales, 12 Cajas Rurales, 7 EDYPIMES (entidades de Desarrollo para las PYMES, 20 ONGs, que tienen una cartera vigente a Diciembre de 1999 de 189 millones de dólares con 225,000 clientes activos, según Villarán. En los últimos 10 años se han incrementado las instituciones crediticias privadas, principalmente con las Cajas Municipales, pero, todavía no tenemos un sistema crediticio específico que regule y promocione sostenidamente al sector, para lo que se requiere un mayor aporte del Estado, a través de programas específicos y de largo aliento.

\section{CONCLUSIONES}

1. El marco regulatorio sobre la estructura y funcionamiento de las micro y pequeñas empresas, en general, ha sido modificado en los últimos 15 años, por tres dispositivos legales: la Ley dictada en el gobierno de Fujimori (1997 que crea PROPYME); la Ley № 28015 (2003) dada en el Gobierno de Toledo y la promulgada por García, a través del D.L. 1086 y su Reglamentación, a través del D.L. № en el año 2008. La última de estas leyes que está en vigencia, elimina PROPYME y las 22 agencias estatales promocionales sustituye, modifica, amplía y/o elimina derechos, formas empresariales de organización y tributación, así como cambios en el régimen laboral de los trabajadores, y en los consiguientes sistemas de de remuneraciones y beneficios sociales, entre otros, conduciendo a una relativa insuficiencia en el uso y aplicación del carácter promocional, así como en un limitado conocimiento por parte de los microempresarios.

2. Segunda. Las políticas públicas que enmarcan la actual administración de las micro y pequeñas empresas artesanales, constituyen fortalezas organizativas, a partir del espíritu emprendedor de los artesanos y por el carácter promocional que orientan su formalización e inducen su inserción rápida en el sistema crediticio o de micro financiamiento, que ha colocado al país en el primer lugar de Latinoamérica en el sistema de micro finanzas privadas y municipales. 
3. Un rasgo característico de las micro y pequeñas empresas artesanales está en su régimen laboral- familiar. El autoempleo, o el subempleo o desempleo estacional, distinguen a las unidades empresariales artesanales, ya que por su ubicación geográfica (medio rural), la comercialización y empleo de innovaciones tecnológicas limitan su competitividad.

4. Este rasgo está asociado a la informalidad, por lo que las políticas públicas y las iniciativas privadas tienden a superarla mediante procedimientos expeditivos que disminuyan los costos de su formalización.

5. La autorización municipal y los registros y permisos, así como el acceso al crédito promocional y a la innovación tecnológica, constituyen un procedimiento que definen a las Mypes artesanales, dada su articulación con la actividad turística y el carácter promocional de los productos destinada a su comercialización, dentro y fuera del país. En este sentido, la exportación artesanal, obliga recordar las obligaciones laborales y tributarias, así como los compromisos con los clientes extranjeros y las exigencias propias de calidad y competitividad comercial.

6. El régimen laboral de las micro y pequeñas empresas artesanales dedicadas a la exportación, se rige por lo dispuesto en el D.L. № 1086 , en las que se regula el periodo vacacional, se reconocen CTS, gratificaciones y derecho al sueldo mínimo, bajo el rubro de "remuneración decente", pero que dentro de cada empresa familiar (micro o pequeña empresa), adquiere, diversos matices que incumplen estas disposiciones, dado el carácter informal de algunas de sus actividades.

7. Esto se debe a la vulnerabilidad económica dado el carácter familiar en el que se abordan las remuneraciones a los trabajadores familiares, relacionadas, además con el origen, volumen y tipo de de artesanía elaborada.

8. La producción y promoción artesanal con fines de exportación, refleja el interés estatal por promover las expresiones artísticas creadas en el mundo popular, que recrean y valoran diversas expresiones monumentales, arqueológicas, folklóricas, etc. de innegable valor cultural para nuestra identidad nacional.
9. La principal limitación de su desarrollo y expansión se encuentra en la ausencia de políticas de investigación sobre la creatividad, innovación tecnológica y mejores prácticas de nuestros artesanos, para difundir nacional e internacionalmente las artesanías que reflejan, de distinta manera, nuestra identidad nacional.

10. La Ley del Artesano y del Desarrollo de la Actividad Artesanal (Ley № 29073) es un encargo al Ministerio de Comercio Exterior y Turismo. Por tratarse de una actividad que merece principalmente el apoyo estatal, dentro de un modelo de desarrollo neoliberal, no se instrumentaliza administrativamente ni se le otorga los recursos presupuestales para cumplir con su articulado.

11. Se otorga al Mincetur la clasificación nacional de líneas artesanales y a los Gobiernos Regionales y Municipalidades provinciales y distritales, la promoción de la actividad artesanal, incentivando la comercialización nacional e internacional. Las acciones del sistema de información para la promoción y desarrollo del artesano, son solo buenas intenciones.

12. Una gran limitación del desarrollo artesanal, se encuentra en la capacitación. Más allá de la habilidad y creatividad innata de nuestros artesanos, se requiere de un apoyo institucional dedicado a mejorar, perfeccionar, innovar y demostrar opciones u alternativas que plasmen objetos de una mayor demanda, sin perder identidad ni valor cultural.

13. Si a ello se añade las limitaciones por la falta de información sobre productos, precios y mercados, se tendrá una idea de cuán insuficiente es el apoyo estatal en el desarrollo de las micro y pequeñas empresas dedicadas a la exportación.

\section{LITERATURA CITADA}

ADEX Nuevo Concepto de la Industria Manual. Boletín Informativo №45 Lima 1996.

ANDER EGG, Ezequiel. "Técnicas para la recogida de datos e información." 1르 Edición. Editorial Distribuidora Lumen SRL. Buenos Aires. 2003. 
ASCAÑO, Jorge "Ceramica de Chulucanas" Asociación de Exportadores (ADEX) y Agencia de Estados Unidos para el Desarrollo Internacional (USAID/MSP), 1999Perú.

BAYONA, Claudia "La artesanía peruana en los mercados internacionales: Un nuevo concepto de la industria manual "Organización de Estados Iberoamericanos Para la Educación, la Ciencia y la Cultura Colombia 2009

BERNNER CAYCHO, Juan Carlos. Dirección nacional de la MYPOE. Exposición Chimbote. 2005.

ADEX Boletín De Exportaciones Regionales Elaborado por el Departamento de Inteligencia Comercial Enero-Marzo 2010

CARRASCO DÁVILA Alan F "La Micro y Pequeña Empresa Mexicana”, Observatorio de la Economía Latinoamericana, Número 45, Julio 2005, en http://www.eumed.net/cursecon/ecolat/mx/2005/afcd-mpymem.htm.

Centro de Promoción de la Pequeña y Micro Empresa (Prompyme) Ministerio de Trabajo y Promoción del Empleo. La situación de la micro y pequeña empresa en el Perú, pp 1-10. 2005, setiembre.

CERDA GUTIÉRREZ, Hugo. "La Investigación Total. La Unidad Metodológica en la Investigación Científica. Cooperativa Editorial Magisterio. Bogotá. 1997.

Comisión Europea de la UE. Recomendación 2003/361/CE de la Comisión, de 6 de mayo de 2003, sobre la definición de microempresas, pequeñas y medianas empresas. Diario Oficial L 124 de 20.5.2003.

COPEME "Memoria 2008-2009" Lima, abril del 2010

Decreto. Legislativo. $\mathrm{N}^{\circ}$ 1086.- Decreto Legislativo que aprueba la Ley de Promoción de la Competitividad, Formalización y Desarrollo de la Micro y Pequeña Empresa y del Acceso al Empleo Decente Diario Oficial El Peruano Página № 375103

Decreto Legislativo 822 - Ley Sobre El Derecho De Autor 23 de abril de 1996 (publicado el 24 de abril de 1996)

D.S. № 022-2004-ED.- Reglamento de Educación Técnico-Productiva Diario Oficial El Peruano Página № 281325 Lima
DEREK LEEBAERT, E "La Contribución de la Pequeña Empresa a la Expansión Económica de los Estados Unidos", de en http://usinfo. state.gov/journals/ites/0106/ijes/leebaert. htm, Obtenido en Febrero del 2007.

ESPINOZA HERRERA, Nemesio "Creación y Gestión de Micro y Pequeñas Empresas" Editorial San Marcos 2008 Pp.201

FLEITAN Jack," Negocios Exitosos", de Mc Graw Hill Interamericana Editores, 2000, Pág. 22.

Fondo Para el Desarrollo de Social de la Ciudad de México (FONDESO)," Clasificación de la Micro y Pequeña Empresa en México», http://www.fondeso.df.gob.mx/doc_interes/detalleDocumento.html, obtenido en Febrero del 2007.

Guía Artesanal Turística. MINCETUR 2009 Pp9

HERNÁNDEZ SAMPIERI, Roberto y otros. Metodología de la Investigación. 4a Edición. Edit. Mc Graw Hill. México. 2006.

LEY № 28015 03/07/2003” Ley De Promoción Y Formalización De La Micro Y Pequeña Empresa” D. S. № 009-2003-TR Diario El Peruano Página № 356576 Lima

Ley Del Artesano Y Del Desarrollo De La Actividad Artesanal 29073 En Lima, julio 2007.

LÉVANO DE ROSSI, Cecilia Elaboración De Estadísticas De La Micro Y Pequeña Empresa, Dirección Nacional De La Micro Y Pequeña Empresa 2005

MALETTA, Héctor. Epistemología Aplicada. Metodología y Técnica de la producción Científica. CIES. CEPES. Universidad del Pacífico. Lima. 2009.

MATHEWS JUAN CARLOS El significado de la competitividad y oportunidades de internacionalización para las mypes. Nathan Associates Inc, 2009.

MATSUSHITA, Konosuke. Claves de un buen gerente. Lima, edic. Kyodai Trading Corporation S. A. 1996.

MINCETUR Resumen de Exportaciones 2009 Oficina General de Estudios Económicos

MARTíNEZ, Miguel Nuevos Métodos de Investigación sobre el Comportamiento Humano. Editorial Universo. Lima. 1998. 
MINCETUR "Plan Estratégico Nacional Exportador 2003 - 2013” (Penx) 2004.

Ministerio de la Producción, Gobierno del Perú. (28-06-08). Decreto Legislativo 1086:" ley de promoción de la competitividad, formalización y desarrollo de la micro y pequeña empresa y del acceso al empleo decente".

Ministerio de la Producción (PRODUCE) "Ley de Promoción de Microempresas y Pequeñas Empresas Decreto Legislativo 705” http:// www.produce.gob.pe/industria/normatividad/micro_empresa.php, obtenido en Febrero del $\overline{2} 007$.

Ministerio de la Producción (PRODUCE) “Ley Artesanal y del Desarrollo de la Actividad Artesanal"

Ministerio de la Producción (PRODUCE) "Ley № 28015 DE Promoción las Pequeñas y Micro Empresas."

OIT. Conferencia Internacional del Trabajo, 90a․ Reunión, Ginebra, 2002. Resolución relativa al trabajo decente y la economía informal. Ginebra, 2002.

PERRY, G., O. Arias, P. FAJNZYLBER, W. MALONEY, A. MASON y J. Saavedra." Informalidad: Escape y exclusión “. Estudios del Banco Mundial sobre América Latina y el Caribe. Banco Mundial, 2007

Preguntas Más Frecuentes del Programa de Desarrollo Empresarial, de la Agencia Federal para el Desarrollo de la Peque- ña Empresa (SBA), http://www.sba.gob/ español/8apreguntas.html, Febrero 2007.

PROMPERU Artesanías en el Perú Hecho el Depósito Legal en la Biblioteca Nacional del Perú 2006 Pp 25.

PROMPERU Turismo rural en el Perú Hecho el Depósito Legal en la Biblioteca Nacional del Perú 2007 Pp 124.

PROMPERU Evolución de las Exportaciones Peruanas Enero - Marzo 2010 Comisión de Promoción del Perú para la Exportación y el Turismo Lima export.promperu.gob.pe/ stat/pr_modprot.asp

Reglamento Del Registro Nacional Del Artesano Y Del Consejo Nacional De Fomento Artesanal, De La Ley № 29073- Ley Del Artesano Y Del Desarrollo De La Actividad Artesanal Decreto Supremo № 001-2008-MINCETUR

\section{PAGINAS WEB:}

http://www.regionloreto.gob.pe/web_dircetura/artesania/artesania.htm

http://asociacion.ciap.org/?lang=es

http://www.adonde.com/peru-peru/artesaniasperuanas/

http://www.oei.org.co/sii/entrega16/art01.htm

http://www.artesaniasdelperu.gob.pe/Instituciones/dircetur.aspx

http://exportacionesdelperu.blogspot. com/2010/03/se-reactiva-la-exportacion-de.html 